\title{
Electrochemical Study of Nitrobenzene Reduction Using Potentiostatic Preparation of nephrolepis Leaf Like Silver Microstructure
}

\author{
R. Karthik ${ }^{1}$, Mani Govindasamy ${ }^{1}$, Shen-Ming Chen ${ }^{1, *}$, Veerappan Mani ${ }^{1,2}$, Rajaji Umamaheswari ${ }^{3}$, \\ T. Shunmuga Thain Balamurugan ${ }^{4}$ \\ ${ }^{1}$ Department of Chemical Engineering and Biotechnology, National Taipei University of Technology, \\ Taipei, Taiwan 106 (ROC) \\ ${ }^{2}$ Graduate Institute of Biomedical and Biochemical Engineering, National Taipei University of \\ Technology, Taipei, Taiwan (ROC) \\ ${ }^{3}$ Department of Chemistry, St. Joseph's College (Autonomous), Tiruchirappalli-620 002, Tamil Nadu, \\ India \\ ${ }^{4}$ School of Chemistry, Bharathidasan University, Tiruchirappalli-620 024, Tamil Nadu, India \\ *E-mail: smchen78@ms15.hinet.net
}

doi: $10.20964 / 2016.07 .63$

Received: 26 March 2016 / Accepted: 29 April 2016 / Published: 4 June 2016

Nephrolepis leaf-like silver microstructures (NLLS-Ag) were prepared through a single step potentiostatic electrodeposition strategy and employed for the electrochemical reduction of nitrobenzene (NB). First, the NLLS-Ag microstructures were prepared on glassy carbon electrode (GCE) from aqueous solution of silver nitrate. The prepared NLLS-Ag microstructures were characterized by scanning electron microscopy, Energy-dispersive X-ray spectroscopy studies, X-ray diffraction and electrochemical methods. At NLLS-Ag/GCE, well-defined reduction peak corresponding to the reduction of NB was observed at lower overpotential with highly enhanced peak currents. The influences of different scan rates and different $\mathrm{pH}$ were investigated. An amperometric sensor is fabricated which exhibited excellent electroanalytical parameters towards NB, such as wide linear range of $0.05-38.8 \mu \mathrm{M}$ and low detection limit of $0.01 \mu \mathrm{M}$. Moreover, the sensor exhibits good repeatability, reproducibility and stability. Besides, Practical applicability has been addressed in biological sample which presents appreciable recovery results.

Keywords: Metal Nanoparticles, Nanotechnology, Nitrobenzene, Electrochemical sensor, Electrocatalysis, Modified electrode

\section{$\underline{\text { FULL TEXT }}$}


(C) 2016 The Authors. Published by ESG (www.electrochemsci.org). This article is an open access article distributed under the terms and conditions of the Creative Commons Attribution license (http://creativecommons.org/licenses/by/4.0/). 